\title{
The Effect of Learner-generated Illustrations on the Immediate And Delayed Recall of English Idioms
}

\author{
Afrouz Aeineh (Corresponding author) \\ Department of English Language, Faculty of Literature and Humanities, University of Guilan, Rasht, Iran \\ E-mail: Afrouz_Aeineh@yahoo.com \\ Saeed Moeeni \\ Department of English Language, Faculty of Literature and Humanities, Hakim Sabzevari University, Sabzevar, Iran \\ E-mail: Smoeeni01@gmail.com \\ Hamideh Merati \\ Department of English Language, Islamic Azad University - South Tehran Branch, Tehran, Iran \\ E-mail: Hamideh.Merati@outlook.com
}

Doi:10.7575/aiac.alls.v.5n.3p.28

URL: http://dx.doi.org/10.7575/aiac.alls.v.5n.3p.28
Received: $02 / 04 / 2014$

Accepted: 06/05/2014

\begin{abstract}
The present study investigated the effect of learner generated illustrations on the immediate and delayed idiom recall of Iranian EFL (English as a foreign language) learners. To accomplish this end, 40 female students participated in this study. A placement test (Quick Placement Test, Version 2) was administered to the participants to ascertain that they were all at intermediate level of proficiency. Since the design of the study was quasi experimental, they were randomly assigned to control (N: 20) and experimental (N: 20) groups. A pretest of idioms was given to the participants to ensure that they were homogeneous in terms of their knowledge of idioms. Both groups were provided with the clarification of idioms through definitions and examples. However the experimental group was required to draw their own mental image of the idioms on a paper. At the end of the treatment, students took an immediate posttest of idioms. After an interval of 2 weeks, a similar posttest was given to the students to examine the delayed recall ability of the learners. The obtained results through an independent samples t-test indicated that the experimental group slightly outperformed the control group on immediate posttest, but the difference was not statistically significant. However the results on the delayed posttest suggested that there was a significant difference between the two groups and the participants in the experimental group had stronger delayed recall ability.
\end{abstract}

Key words: Learner-generated illustrations, immediate and delayed recall, English idioms, drawing

\section{Introduction}

Figurative idioms were neglected in earlier days of SLA research but recently it has received great attention in the SLA literature. The lack of concern for idioms could have had three reasons: First, language was assumed to be made of grammar rules and individual words. Second, idioms were considered to serve stylistic purposes limited to rhetoric and poetry. Third, they assumed the meaning of idioms as absolutely unpredictable. So it was believed that it couldn't be taught. The only achievable way to learn idioms was blind memorization. However, SLA research has now found out the significance of learning idioms and prefabricated patterns (Boers, Demecheleer \& Eyckmans, 2004).

Human cognition is unique in that it has become specialized for dealing simultaneously with language and with nonverbal objects and events. Moreover, the language system is peculiar in that it deals directly with linguistic input and output (in the form of speech or writing) while at the same time serving a symbolic function with respect to nonverbal objects, events, and behaviors. Any representational theory must accommodate this dual functionality. (Paivio, 1986, p.53).

Paivio (2006) expresses that Dual Coding Theory (DCT) includes two separate subsystems; one of which has been specialized for the verbal aspect dealing with language and the other is specialized for nonverbal (imagery) aspect. He attempts to give the same amount of importance to both verbal and nonverbal processing. These two systems have internal representations which are activated when the learner realizes, manipulates and considers the word in his/her mind.

Idioms are commonly used in formal and informal written and spoken language. Hornby (2006) defined idiom as" a group of words whose meaning is different from the meanings of the individual words." He also defines idiomatic as "containing expressions that are natural to a native speaker of a language (P.770)."

While reading a book or watching a movie, it is not surprising to encounter loads of idioms. Students often feel frustrated because they are unable to understand phrases or sentences that cannot be understood literally, although they 
spend countless hours studying endless grammar structures. Sometimes they know the meaning of all the words and grammar structures in a phrase but the meaning of the phrase is still ambiguous. Baker (2011) state that what makes idiom learning difficult to learn and interpret is the fact that the whole is greater than the sum of its parts. It means that you cannot get the meaning of idioms by understanding the words composing them.

Many studies have examined the effect of different techniques on teaching and learning idioms. However this study is intended to consider the issue from a new prospect and investigate the effect of self-generated illustrations on short term (immediate) and long term (delayed) recall of idioms.

\section{Literature review}

Idioms are of great importance in second language learning, although they are really difficult to comprehend and produce. Using idioms makes language learners fluent in speaking and using figurative competence in foreign language shows learners' communicative competence ( Zarei \& Rahimi, 2012).

According to Scrivener (2011) "meaning is not as precise as we might feel it to be." He believes that is because different people from different cultures have had different interpretation of the world around them. This can be one source of difficulties for students and teachers. To help learners, it is vital to analyze the meaning of words as effectively as we can. In literature, many studies have been done to find out an appropriate way for teaching and learning idioms. Different techniques have been used to facilitate learning of idioms such as etymology, contextual pragmatic clues, using pictures, etc. In this study, two related studies are mentioned in depth.

Saffarian, Gorjian \& Bavizadeh (2013) conducted a study on "the effect of using pictures on EFL learners' retention of body idiomatic expressions". 40 males and 40 females out of 120 were chosen to participate in this study which lasted for ten sessions. They were at the pre-intermediate level. The experimental group was provided with six pictures of body idioms, their definition and description of their usage. However for the control group the teacher didn't use the pictures. They were supplied with similar idioms and their definition by the instructor. 10 days after the treatment, the groups were given a post-test to see the effect of using pictures on the learners' recall and retention of idioms. Findings indicated that the participants of experimental group recalled and retained idiomatic expressions better than the control group. To sum up, they claimed that using visual images can promote students' retention of idioms to a significant extent.

Baker (2011) investigated the effects of visual images on the immediate and delayed recall of idioms when taught with etymological elaboration. 42 participants took part in this study. They were in the highest level of English for Academic Purposes (APA) course of a college. The study aimed to compare the effects of presenting actual illustrations and developing their own mental image of a scene. The control group was provided with description of the origins and definition of 10 idioms. They could also see the corresponding phrases and illustrations of etymologies. The experimental group was also exposed to the description of the origins and definition of the same idioms. The difference is that the descriptions provided were used to encourage participants to make their own mental images of the stories. In other words the control group was exposed to ready-made images of the idioms but the experimental group was encouraged to create self-generated imagery. They could only see the idiomatic phrase but not the pictures. Two quizzes were given to both groups to check their short-and-long term recall of idioms on two different occasions. The firs quiz was administered immediately after treatment and the other one was given three weeks later. The result of the study indicates that neither technique was clearly better than the other. It showed that although the experimental group gained slightly higher scores, the differences between the groups were not statistically significant. However the variance on both quizzes in experimental group was less than the variance in the control group. It shows that there was a significant difference between groups in delayed posttest and it can be concluded that self-generated imagery illustrated a more consistent result.

\section{Research questions}

1: Does self-generated drawing of idioms improve Iranian EFL learners' immediate idiom recall?

2: Does self-generated drawing of idioms improve Iranian EFL learners' delayed idiom recall?

\section{Research hypotheses}

H0 (1): There is no statistically significant difference between the immediate idiom recall of Iranian EFL learners who draw their mental images of idioms and students who do not.

H0 (2): There is no statistically significant difference between the delayed idiom recall of Iranian EFL learners who draw their mental images of idioms and students who do not.

\section{Methodology}

\subsection{Participants}

The participants of the study included 40 Iranian EFL learners. They were randomly assigned to experimental (N: 20) and control group (N: 20). They were all females and their age was around 14 to 18 . The design of the study was quasiexperimental since the participants were not randomly selected, but randomly assigned to the control and experimental group. 


\subsection{Instrument}

The first instrument used in this study was Quick Placement Test (Version 2) to ensure that all the participants were at intermediate level of language proficiency. Then a pretest of idioms was given to the students to make sure that they were homogeneous in terms of knowledge of idioms. After the treatment a post test was given to the students to examine the effect of self-generated illustration on immediate recall of idioms. A delayed posttest was administered to show long term effect of this technique on learning idioms.

\subsection{Procedure}

20 idioms were selected by the researchers. Researchers tried to include idioms which were concrete and easy to illustrate. 2 idioms were taught each session. The study lasted for 10 sessions; each session 45 minutes. In the experimental and the control group the teacher first clarified the meaning of the idioms by providing examples and stories. Whenever the teacher felt that the students couldn't get the meaning from stories and examples, the teacher provided them with definition of idioms. The only difference between the control and the experimental group was that the latter had to draw their own mental image of the idioms on a paper. In both groups the students had small group works to discuss the idioms after they were taught by the teacher. In the control group they could talk about the stories which were told by the teacher or they could talk about the idiom usage. In the experimental group, in addition to talking about the stories, definition and usage, the students could show their drawing to each other and explain about their artifacts.

\section{Result and discussion}

Before starting the treatment an idiom test was selected as the pretest and the learners were asked to take the test to make sure that they don't know the idioms which they were going to be taught during the treatment; therefore, the data were entered in the software and an independent sample t-test was conducted to compare the pretest scores for the control group and the experimental group. The results provided in the output showed that there was no significant difference in scores for the control group $(\mathrm{M}=2.05, \mathrm{SD}=1.60)$ and the experimental group, $\mathrm{M}=2.20, \mathrm{SD}=1.32 ; \mathrm{P}=.74$ (two tailed). The mean score and $\mathrm{P}$ value strongly proves that the two groups are homogeneous and also neither of them has much prior knowledge about the materials of the treatment. Table 1 depicts the information related to the pretest.

Table 1. Independent Samples T-Test for Pretest

Mean Std. Deviation Std. Error Mean $\quad t \quad$ df $\quad$ Sig. (2-tailed)

\begin{tabular}{lllllll} 
Exp. & 2.20 & 1.32 & .29 & & & \\
& & & & & & \\
Con. & 2.05 & 1.60 & .323 & & 38 & .749 \\
\hline
\end{tabular}

An independent sample t-test was also conducted to compare the post test scores for the control group and the experimental group. The results revealed that the experimental group $(\mathrm{M}=17.05, \mathrm{SD}=1.60)$ performed slightly better than the control group but the difference was not statistically significant $(\mathrm{M}=16.20, \mathrm{SD}=1.23 ; \mathrm{P}=.069)$.

Table 2. Independent Samples T-Test for posttest

Mean Std. Deviation Std. Error Mean t $\quad$ df $\quad$ Sig. (2-tailed)

\begin{tabular}{lllllll} 
Exp. & 17.05 & 1.60 & .35 & & & \\
Con. & 16.20 & 1.23 & .27 & & & \\
\hline
\end{tabular}

Another independent sample t-test was conducted to compare the delayed post test scores. The result indicated that the experimental group $(\mathrm{M}=16, \mathrm{SD}=2.02)$ was significantly better than the control group $(\mathrm{M}=14.55, \mathrm{SD}=1.66 ; \mathrm{P}=.01)$.

Table 3. Independent Samples T-Test for delayed posttest
Mean Std. Deviation Std. Error Mean
$\mathrm{t} \quad \mathrm{df}$
Sig. (2-tailed)

\begin{tabular}{lllllll} 
Exp. & 16.00 & 2.02 & .45 & & & \\
Con. & 14.55 & 1.66 & .37 & & & \\
\hline
\end{tabular}


Regarding the first research question of this study, the results revealed that self-generated drawing of idioms cannot improve immediate idiom recall of EFL learners significantly. Therefore the first null hypothesis is not rejected since the difference in the performance of the control and experimental group is not prominent.

In terms of the second research question, it can be claimed that self-generated drawing of idioms can improve Iranian EFL learners delayed idiom recall significantly. As a result the second null hypothesis is rejected and we can conclude that although drawing mental image of idioms may not affect students' short-term recall considerably, it makes learning long-lasting and durable.

\section{Conclusion}

The current study intended to investigate whether there was a significant difference in short-term and long-term idiom recall for the control and experimental groups. The result of this study indicated that illustration can have a slight effect on immediate retention of idioms. However self-generated illustrations had a significant effect on delayed retention of idioms.

The findings of this study can have implications for teachers. They can apply this technique for teaching idioms. Although illustrations and drawing may not have outstanding effect on immediate recall, it has a significant effect on their delayed recall. The present study can also have implications for students in that instead of rote learning and blind memorization of idioms, they can have an enjoyable experience by drawing the concept of idioms.

In this study the effect of drawing and learner generated illustrations was compared with merely providing definitions and stories. It is suggested that future research focus on the comparison of this kind of illustrations with providing ready-made pictures or etymological elaborations to see which one is more effective in learning idioms.

\section{Limitations}

Undoubtedly this study had some limitations. The first limitation was the number of participants which was limited to 20 students in each group. Another limitation of this study was their sex which was limited to females.

\section{References}

Baker, S. (2011). The effects of visual images and imagery on immediate and delayed recall of idioms by English language learners. (M.A thesis, Hamline university, 2011).

Boers, F., Demecheleer, M., \& Eyckmans, J. (2004). Etymological elaboration as a strategy for learning idioms. In P. Bogaards, \& B. Laufer (Eds.), Language learning \& language teaching: Vocabulary in a second language (pp.53-78). Amsterdam/ Philadelphia : John Benjamins Publishing company.

Hornby, A.S. (2006). Oxford advanced learner's dictionary ( $7^{\text {th }}$ ed.). Oxford: Oxford university press.

Paivio, A. (1986). Mental representations: A dual coding approach. New York: Oxford science publication.

Paivio, A. (2006). Dual coding theory and education. University of Western Ontario. Paper presented at Pathways to literacy achievement for high poverty children. The university of Michigan school of education.

Saffarian, R, Gorjian, B, \& Bavizadeh, K. (2013). The effect of using pictures on EFL learners' retention of body idiomatic expressions. Journal of comparative literature and culture, 2(4),150-154.

Scrivener, J. (2011). Learning teaching: The essential guide to English language teaching. Oxford: Macmillan.

Zarei, A. A., \& Rahimi, N. (2012). Idioms: Etymology, contextual pragmatic clues and lexical knowledge in focus. Germany: Lambert academic publishing.

\section{Appendix}

List of idioms

1. Sugar the pill: do s.th to make s.th unpleasant more acceptable

2. Kick the bucket: die

3. To get cold feet: to become nervous/frightened right before sth you had planned to do

4. To be left holding the baby: to be left to deal with a problem alone

5. To be behind the bars: to be in prison

6. Be on a knife edge: be in a difficult situation

7. ring a bell: is familiar to you, but you don't remember

8. to give a hand: to help someone

9. let the cat out of the bag: tell the secret so that others understand it

10. pull someone's leg: the same as you are joking

11. get out of hand: get out of control

12. to break the ice: to start a social conversation warmly

13. the ball is in your court: to say that you have a control of the situation

14. be in hot water: be in trouble

15. put all your eggs in one basket: to put all of something you have in the same area

16. Birds of a feather (flock together): similar people tend to spend time with each other.

17. Be a basket case: be a crazy person

18. know something like the back of your hand: to be very familiar with something

19. be on the ball: to be thinking well and reacting quickly

20. get the sack: to be fired 